\title{
Imunoglobulina A Salivar (IgA-s) e Exercício: Relevância do Controle em Atletas e Implicações Metodológicas
}

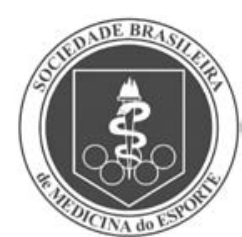

Artigos de ReVisão

\section{Salivary Immunoglobulin A (s-IgA) and Exercise: Relevance of its Control in Athletes and Methodological Implications}

\author{
Rafael Pires da Silva' \\ Antônio José Natali \\ Sérgio Oliveira de Paula ${ }^{2}$ \\ Jamille Locatelli' \\ João Carlos Bouzas Marins
}

1. Departamento de Educação Física, Universidade Federal de Viçosa - UFV.

2. Departamento de Biologia Geral, Universidade Federal de Viçosa - UFV.

\author{
Endereço para correspondência: \\ Rafael Pires da Silva \\ Universidade Federal de Viçosa. \\ Departamento de Educação Física. \\ Laboratório de Performance \\ Humana - LAPEH. \\ Av. PH Rolfs, s/n - 36571-000 - \\ Viçosa, MG. \\ Tel.: (31) 3899-2258; \\ fax: (31) 3899-2249. \\ E-mail: rafael.pires@ufv.br
}

Submetido em: 21/11/2008

Versão final recebida em: 15/07/2009 Aceito em: 28/07/2009

\begin{abstract}
RESUMO
O objetivo do presente estudo é realizar uma análise e discussão dos principais achados envolvendo o comportamento da imunoglobulina A salivar (IgA-s) em relação ao estímulo do exercício e evidenciar a importância de seu controle em atletas. O exercício físico é um importante modulador das características do sistema imune, sobretudo do comportamento da lgA-s, componente fundamental na proteção de infecções do trato respiratório superior (ITRS). No entanto, a relação direta entre baixas concentrações de lgA-s e ITRS precisa de mais evidências para ser confirmada. As concentrações de lgA-s durante e logo após um exercício intenso diminuem, deixando o indivíduo mais suscetível à infecção, porém, atletas envolvidos em atividades extenuantes não são clinicamente imunodeficientes, comparados com indivíduos sedentários. Essas modificações são transitórias, com retorno aos valores normais após aproximadamente 48 horas de repouso. A razão dessas alterações não é clara, mas se apresenta multifatorial: elevação de hormônios estressores; fatores nutricionais; ação de espécies reativas de oxigênio; e estresse psicológico. Apesar do efeito transitório das alterações provocadas nos elementos do sistema imune frente ao exercício, observa-se diferença na variabilidade da lgA-s em populações com diferentes níveis de condicionamento. Diferenças metodológicas - como o protocolo de exercício, o método de coleta, armazenamento e manipulação da saliva, a forma de expressão da lgA-s, o nível de hidratação, o controle da dieta, a sazonalidade do período de competição, a aclimatação entre outros fatores - devem ser levadas em consideração para comparação entre os estudos. Além disso, ajudam a explicar, em parte, os resultados adversos envolvendo exercício moderado e os intermitentes, em que se encontram aumento, redução e até ausência de alteração nos níveis de lgA-s. Investigações de elementos inovadores, como os toll-like receptors, e o avanço tecnológico podem colaborar para aumentar as evidências sobre o tema.
\end{abstract}

Palavras-chave: sistema imunológico, exercício físico, infecção.

\begin{abstract}
The present study aimed to discuss the main findings involving salivary immunoglobulin A (s-lgA) and exercise and evidence the importance of the control in athletes. Exercise is a great modulator of immune system characteristics such as the s-IgA that exerts important defense against upper respiratory tract infections (URTI). However, more evidence is needed to confirm a direct association between low levels of s-IgA and URTI. The level of s-lgA decreases after a high-intense exercise, increasing thus, the individual's susceptibility to infection, but athletes engaged in exhausting exercise are not clinically immune-deficient compared with sedentary subjects. The changes in s-lgA are transitory returning to normal status in approximately 48-h rest. The reason of these alterations remains unclear, but many causes have been investigated: hormones stressors rise; nutrition influences; action of reactive oxygen species, psychological stress. Despite the transitory effects of the exercise on the immune system, the variability in s-lgA differs in populations with different fitness levels. Differences in exercise protocols, saliva collection, manipulation or storage methods, the method used to assess s-lgA, subject's hydration status, dietary control, competition's seasonality, acclimatization,among other factors should be considered to compare different studies. In addition, these factors could partially explain the adverse results of studies involving moderate and intermittent exercise that have found increase, decrease and no changes in s-lgA levels. Investigations of recent immunologic issues such as the toll like-receptors and the advances in technology may contribute to increase the evidence on this issue.
\end{abstract}

Keywords: immune system, physical exercise, infection.

\section{INTRODUÇÃO}

A influência da atividade física sobre o contexto do sistema imunológico tem merecido atenção relevante no cenário científico ${ }^{(1-4)}$, principalmente quando se relaciona o exercício com a incidência de infecções do trato respiratório superior (ITRS), que se associa, por sua vez, à região da mucosa salivar, cuja responsabilidade principal de defesa é da imunoglobulina de classe A $(\operatorname{lgA}-\mathrm{s})^{(5)}$. De fato, alguns estudos têm demonstrado que baixa concentração de $\operatorname{lgA}$-s reduz a resistência a infecções, o que representaria um risco ao atleta engajado em situações competitivas ${ }^{(6,7)}$. Entretanto, elementos principalmente de ordem metodológica, e que serão discutidos no presente estudo, demonstram que a associação direta entre baixas concentrações de IgA-s e ocorrência de ITRS precisa ser analisada com cautela.

O exercício físico pode resultar em respostas tanto positivas como negativas à imunidade, dependendo do modelo de estresse a que o corpo é submetido ${ }^{(2)}$. Em situações de atividade física extenuante, como no 
caso dos atletas envolvidos em longos períodos de treinamento intenso, o aumento da suscetibilidade a infecções é amplamente observado (8-11). A redução de lgA-s pode ser verificada tanto durante o período de treinamento exaustivo ${ }^{(7,12,13)}$ como logo após a sessão de treino ${ }^{(14-16)}$. Exercícios físicos de intensidade moderada, ao contrário, estariam relacionados com a melhora do sistema imunológico, com redução da incidência de ITRS e aumento das concentrações de lgA-s durante o período de repouso ${ }^{(17-19)}$. Outros estudos, contudo, não observaram alterações na lgA-s em exercícios de moderada intensidade ${ }^{(20)}$. Há ainda escassez de trabalhos dedicados a investigar a resposta da IgA-s durante o exercício intermitente, em esportes coletivos ou em situação real de competição.

O controle prático e não invasivo da concentração salivar de lgA vem sendo apontado como um indicador importante do estado imunológico da mucosa dos atletas ${ }^{(21)}$, ajudando treinadores e comissão técnica na elaboração de uma periodização de treinamento melhorado em relação à proteção imune. Implicações referentes ao nível de condicionamento, fatores nutricionais, estresse psicológico, entre outros, emergem como potenciais modificadores da resistência imune da mucosa salivar relacionada com o exercício e também devem merecer destaque de investigação. Da mesma forma, a razão e o modo pelo qual o sistema imune responde aos variados estímulos do exercício, assim como os mecanismos que explicam convergência para determinada resposta específica, não estão completamente esclarecidos.

O objetivo da presente revisão, portanto, é realizar uma análise e discussão dos principais achados envolvendo o comportamento da IgA-s em relação ao estímulo do exercício, bem como promover uma análise crítica e comparativa dos dados, indicando limites, alcances metodológicos e apontando perspectivas de continuidade do assunto.

\section{MÉTODOS}

Para a realização da presente revisão, foram feitas pesquisas bibliográficas nas bases de dados Medline, PubMed, Scielo e Lilacs utilizando os termos saliva, immune system, immunoglobulin A, secretion, infection, inflammation, exercise upper respiratory tract infections, mucosal salivary e suas traduções para a língua portuguesa em cruzamento e individualmente. A estratégia de busca da literatura forneceu 150 estudos para a seleção inicial. Todos os artigos obtidos na busca eletrônica tiveram seus resumos extraídos e analisados de maneira independente. Foram criteriosamente incluídos estudos que: a) avaliaram os efeitos tanto agudos como crônicos do exercício físico sobre a lgA-s; b) apresentaram limitações e alternativas metodológicas importantes para o estudo da lgA-s. Publicações com foco geral no sistema imune e que contribuiriam para suporte de informações complementares também foram consideradas. Foram filtradas 60 publicações que atenderam aos critérios de inclusão. A partir da obtenção e leitura dos artigos, suas referências bibliográficas foram rastreadas à procura de outros trabalhos potencialmente utilizáveis. Foram considerados artigos publicados nos últimos 26 anos, nos idiomas inglês, português e espanhol, principalmente, artigos originais, de revisão, ensaios clínicos controlados randomizados.

Não foram realizadas restrições quanto à faixa etária, gênero ou modalidade esportiva, mas estudos envolvendo atletas e pessoas saudáveis foram preferencialmente escolhidos, assim como trabalhos em que os modelos metodológicos fossem realizados com seres humanos; entretanto, desenhos experimentais conduzidos em modelo animal que, a nosso ver, contribuiriam para o entendimento do tema, também foram incluídos. Foram excluídos artigos que, mesmo apresentando os unitermos utilizados para busca, não contemplavam a relação entre exercício, sistema imune e lgA-s.

\section{Imunidade das mucosas}

A imunidade humoral representa um braço efetor importante do sistema imune adaptativo, sendo a linha de defesa principal contra microrganismos extracelulares e toxinas microbianas. Essa ação é mediada por moléculas presentes no sangue e nas secreções das mucosas conhecidas como anticorpos, também chamados de imunoglobulinas ${ }^{(22)}$. As imunoglobulinas são um grupo de moléculas proteicas que compartilham muitas similaridades antigênicas, estruturais e biológicas, mas com propriedades altamente específicas, o que lhes permite realizar com eficiência seu papel de anticorpo na defesa do organismo (22); são classificadas, de acordo com suas características físico-químicas e função efetora, em cinco classes ou isótipos, representados pelas letras $A, D, E, G$ e $M^{(23)}$.

A defesa contra microrganismos que entram pelo trato gastrintestinal e respiratório é realizada pelos anticorpos, principalmente pela $\lg$ A, que são produzidos nos tecidos linfoides mucosos e secretados através do epitélio mucoso para o lúmen dos órgãos ${ }^{(1)}$. A lgA participa como agente secundário da imunidade humoral sistêmica, comparada

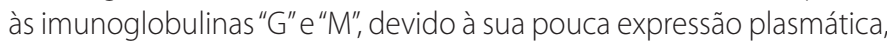
mas se torna decisiva nos fluidos da mucosa, onde sua produção é elevada, atuando: na prevenção da penetração e aderência de patógenos no epitélio mucoso contraídos pela ingestão ou inalação; na neutralização de vírus dentro das células epiteliais durante a transcitose; e na excreção de complexos imunes locais através da mucosa epitelial para a superfície do lúmen ${ }^{(24,25)}$.

Além do tamanho da superfície intestinal, outro fator que também explica a expressão de maiores quantidades de lgA em relação a outras imunoglobulinas é a presença numerosa de células T auxiliares ou linfócito Thelper (Th) na mucosa. As células Th produzem interleucina 5 (IL 5), que é o principal estímulo para diferenciação das células B em $\lg \mathrm{A}^{(26)}$. Diferentes exposições a microrganismos estimulam a troca das células B para os isótipos de imunoglobulina. O fator transformador de crescimento $\beta$ (TGF- $\beta$ ), que é uma citocina produzida por vários tipos celulares na mucosa, também é responsável por induzir essa diferenciação, agindo em colaboração com IL 5 ${ }^{(26)}$.

As imunoglobulinas de classe A possuem duas subclasses ${ }^{(22)}$ : IgA 1, produzida pelas células B da medula óssea, cuja expressão é menor, cerca de 20\%; e lgA 2, foco do presente estudo, que é produzida pelas células B da mucosa, com cerca de $80 \%$ da produção total ${ }^{(1)}$. Uma vez produzida pelos plasmócitos (diferenciados da célula B ativada) na lâmina própria do epitélio das glândulas salivares, a IgA se liga a um receptor poli-lg ou polymeric lg receptor (plgR) na base da célula epitelial, de onde é transportada e liberada por clivagem proteolítica para se juntar a outras substâncias que compõem o muco salivar(26). Alguns estudos têm discutido a respeito do exercício como mecanismo de indução a possível resposta diferenciada na expressão do receptor plgR ${ }^{(27,28)}$. Kimura et al.(29) estudaram a supressão da IgA na saliva de ratos a partir de um exercício intenso e, após quatro dias consecutivos de corrida até a exaustão, foi observada redução significante da expressão do RNAm do receptor plgR, juntamente com expressiva diminuição das concentrações de lgA salivar. O conhecimento da resposta de plgR ao exercício intenso é uma perspectiva de estudo interessante e aponta possibilidades de investigações envolvendo outras intensidades de exercício.

\section{Produção salivar}

A secreção de saliva é regulada pelo sistema nervoso autônomo, sendo composta por uma mistura complexa de secreções das glândulas parótidas, submandibular, sublingual e de outras pequenas glândulas que possuem inervação simpática e parassimpática ${ }^{(28,30)}$. Essas estruturas formam o mais importante reservatório das mais ricas fontes de lgA para proteção do trato respiratório superior. Embora estudos tenham encontrado correlação negativa(31), há hipóteses de que reduções do fluxo salivar podem também diminuir a expressão de $\lg \mathrm{A}^{(32)}$, expondo o indivíduo a riscos de ITRS. Para o ambiente esportivo, isso poderia trazer consequências, como sintomas de inflamação na garganta, congestão, coriza, febre, entre outros, prejudicando o treinamento de atletas e praticantes de atividade física.

Um aumento na atividade do sistema nervoso simpático promove vasoconstrição de vasos sanguíneos e glândulas salivares, limitando o fornecimento de água para a produção de saliva ${ }^{(33)}$. A liberação de no- 
raepinefrina observada durante o exercício prolongado está associada à redução do fluxo salivar ${ }^{\left({ }^{(3)}\right.}$, que, por sua vez, diminui as concentrações de IgA na saliva. Garantir um bom nível de secreção salivar, mesmo durante o exercício, é fundamental para impedir reduções acentuadas nos níveis de IgA-s. Uma forma interessante de assegurar isso é manter o indivíduo hidratado. A ingestão frequente de líquidos ao longo do exercício deixa a boca constantemente molhada, enviando sinais ao sistema nervoso para que a produção de saliva não cesse ${ }^{(35)}$. Dessa forma, esse tipo de ação previne não somente a desidratação(36), como ajuda também a manter facilmente o movimento de saliva na boca, preservando o fluxo salivar e, logo, a concentração de IgA. Nosso grupo observou que os atletas das mais variadas modalidades não possuem o habito de se hidratar durante o treinamento ou competiçãa ${ }^{(37,38)} \mathrm{ou}$ o fazem de forma equivocada, o que gera condição facilitadora para a redução das concentrações de lgA e possivelmente infecções. Walsh et al.(39) observaram que a hidratação durante o exercício seria um estímulo com envolvimento maior no controle do fluxo salivar durante o exercício prolongado do que a própria regulação neuroendócrina. Bishop et al. ${ }^{\left({ }^{(0)}\right)}$ analisaram 15 atletas durante duas horas de ciclismo e confirmaram maior taxa de secreção salivar quando foram ingeridos líquidos durante o exercício, comparada com a de um regime restrito de hidratação. Esses resultados sugerem a necessidade de estabelecer uma conduta contínua de hidratação ao longo do exercício, tendo em vista uma resposta aprimorada na expressão de lgA-s.

A fonte e a forma de coleta da saliva para análise de IgA são pontos interessantes que estão imersos em um viés metodológico de extrema relevância ${ }^{(41)}$, de modo que a utilização de determinados materiais nos estudos deve ser feita com prudência. Como a saliva é composta pela secreção de diversas glândulas e a concentração de lgA varia em relação a essas glândulas, a utilização ou não de estimulantes salivares nos trabaIhos deve ser relatada e descrita corretamente na metodologia, a fim de possibilitar uma comparação mais fidedigna entre os estudos. Até mesmo se houve ou não estimulação mecânica da face por movimentos repetitivos deve ser mencionado, principalmente se for de interesse do estudo discutir a taxa de produção salivar. A coleta de saliva deve ser feita sob condições que permitam mínima interferência na concentração biológica de IgA-s; portanto, deve-se atentar para que os absorventes salivares utilizados para mensuração de outras variáveis sejam sistemas validados para a coleta também de IgA. Condições de manipulação e armazenamento são outras medidas cautelares que devem ser cuidadosamente observadas para manter a integridade da IgA e não comprometer os resultados. $O$ quadro 1 mostra as estratégias metodológicas mais utilizadas para análise do impacto da IgA-s em praticantes de exercícios físicos.

\section{Infecções do trato respiratório superior (ITRS)}

A prática de atividade física, de modo geral, exige mecanismos adaptativos agudos em busca de homeostase, entre os quais o aumento de incursões respiratórias. Durante o exercício de alta intensidade, os movimentos respiratórios ficam ainda mais frequentes e, por vezes, mais profundos, a fim de possibilitar que mais oxigênio seja captado e utilizado para produção de energia, o que ocorre de forma menos expressiva durante o exercício moderado. Esse fato, entretanto, coloca o praticante de atividade física em contato maior com os poluentes do ar, resultando em condição facilitadora para infecção $0^{(42)}$.

Alta incidência de infecções tem sido relacionada com indivíduos com deficiência seletiva em IgA-s ou taxa reduzida do fluxo salivar ${ }^{(43)}$, indicando, assim, uma relação estreita entre concentração de $\lg A$ e risco de infecções ${ }^{(44)}$. Embora ainda não totalmente comprovado, apesar dos fortes indícios, Gleeson et al.(7) encontraram evidências de que a redução nos níveis de IgA-s está associada ao aumento frequente de episódios envolvendo ITRS. Mackinnon e Jenkins( ${ }^{(22)}$, por sua vez, sugerem que pelo menos parte desse aumento da suscetibilidade à ITRS possa ser explicada pelo decréscimo das concentrações de lgA-s, resultante tanto da redução na expressão da referida imunoglobulina como da diminuição do fluxo de saliva.

A falta de consenso quando se relaciona a redução dos níveis de IgA-s com a incidência de ITRS pode se dar por uma limitação metodológica importante, referente à forma de coleta dos dados. Os estudos, em geral, não utilizam diagnóstico médico e aplicam somente questionários para verificar a incidência de ITRS após o exercício, o que pode superestimar a incidência dessas infecções. Da subjetividade metodológica surge a crítica quanto à impossibilidade de se afirmar, seguramente, que os sintomas apontados pelos avaliados são, de fato, causados por agentes infecciosos e não estão sendo confundidos com sintomas de alergia, de inalação de poluente ou de inflamação das vias aéreas (2). Essas reações apresentam sintomatologias semelhantes, porém, possuem etiologia patológica diferenciada. Estudos dedicados à investigação da temática podem, a fim de evidenciar dados mais consistentes, realizar uma análise em laboratório da amostra do material a ser coletado nas vias aéreas, para comprovar a origem da infecção. Entretanto, mesmo quando há uma consulta ao parecer médico, é rara a confirmação do laboratório de verificação da doença, devido ao alto custo da investigação e ao vasto número de patógenos potencialmente associados.

Outro fator que dificulta a análise da correlação entre queda de IgA-s e aumento de ITRS é a variação dos níveis de IgA-s durante o período de infecção. Gleeson et al. ${ }^{(45)}$, constatando sintomas de ITRS após exercício de natação intenso, observaram elevação da IgA-s nos seis primeiros dias, com retorno aos níveis pré-sintomas 11 dias após o primeiro dia da manifestação. Tiollier et al.(44), analisando militares submetidos a treinamento intenso, não observaram diferenças na concentração de IgA-s entre os sujeitos que apresentaram sintomas de ITRS e aqueles considerados saudáveis, o que estaria relacionado com uma possível automodulação das células imunes em busca de homeostase. Esses autores sugerem ainda que a correlação entre IgA e ITRS poderia ser mais bem constatada se fossem identificadas baixas de lgA-s 48 horas antes do aparecimento dos sintomas e realizado em seguida o controle diário dos níveis de IgA-s até o fim da infecção, o que, do ponto de vista científico-investigativo, se torna difícil de ser operacionalizado.

Quando se analisam IgA-s e ITRS, deve-se também atentar para o cuidado de não atribuir à IgA-s toda a responsabilidade de proteção

Quadro 1. Considerações metodológicas importantes em pesquisas com IgA-s

\begin{tabular}{|c|c|c|c|}
\hline Momento de coleta & Forma de coleta & Análise & Expressão dos resultados \\
\hline Mesma hora do dia e mesmo dia da semana. & $\begin{array}{l}\text { A utilização de estimulantes salivares e a higie- } \\
\text { nização da boca com água destilada momentos } \\
\text { antes da coleta ficam a critério do pesquisador } \\
\text { de acordo com o objetivo do estudo. }\end{array}$ & $\begin{array}{l}\text { A saliva é normalmente coletada em recipien- } \\
\text { tes plásticos e armazenada em condições tér- } \\
\text { micas em torno de }-20^{\circ} \mathrm{Ce}-80^{\circ} \mathrm{C} \text {. }\end{array}$ & $\begin{array}{l}\text { Concentração absoluta de } \lg \mathrm{A}\left(\mu \mathrm{g} \times \mathrm{ml}^{-1}\right) \text {. } \\
\text { Concentração relativa ao total de proteína } \\
\left(\mu \mathrm{g} \times \mathrm{mg}^{-1}\right) \text {. }\end{array}$ \\
\hline $\begin{array}{l}\text { Padronizar um momento específico. Ex:: após } \\
\text { horas de sono. }\end{array}$ & $\begin{array}{l}\text { Absorventes sublinguais de algodão são nor- } \\
\text { malmente mais utilizados. }\end{array}$ & $\begin{array}{l}\text { O absorvente é centrifugado por } 10 \text { a } 20 \text { minu- } \\
\text { tos a } 3000 \text { rpm em temperatura ambiente. }\end{array}$ & $\begin{array}{l}\text { Taxa de secreção de lgA. }\left(\mu \mathrm{g} \times \mathrm{min}^{-1} \text { ). Obtida pelo pro- }\right. \\
\text { duto da concentração absoluta pelo fluxo salivar. }\end{array}$ \\
\hline $\begin{array}{l}\text { Recomenda-se não ingerir nada momentos } \\
\text { antes da coleta. } O \text { tempo varia entre } 15 \text { mi- } \\
\text { nutos e } 2 \text { horas a critério do pesquisador, de } \\
\text { acordo com o objetivo do estudo. }\end{array}$ & $\begin{array}{l}\text { O tempo utilizado na espera da produção e } \\
\text { coleta de saliva é normalmente entre } 2 \text { e } 4 \\
\text { minutos. }\end{array}$ & $\begin{array}{l}\text { A lgA é normalmente analisada pelo método } \\
\text { Enzyme-linked immunosorbent assay (ELISA). }\end{array}$ & $\begin{array}{l}\text { Fluxo salivar }\left(\mathrm{ml} \times \min ^{-1}\right) \text {. } \\
\text { Obtido pela razão entre o total de amostra de saliva } \\
\text { produzida em um determinado tempo. }\end{array}$ \\
\hline
\end{tabular}


do trato respiratório superior, uma vez que o mecanismo de defesa não age de forma segmentada. A resposta imune celular também é importante e complementa a resposta imune humoral. A prevalência de uma ou outra resposta durante o exercício vai depender grandemente do tipo de citocina expressa pelo linfócito Th ativado. O linfócito Th se divide em duas classes: classe 1 (Th1), que produz principalmente citocinas que irão ativar a resposta imunológica celular como interleucina 2 (IL 2), interferon- $\gamma$ (INF- $\gamma$ ) e fator de necrose tumoral (TNF); e classe 2 (Th2), que produz principalmente fatores relacionados com a promoção da imunidade humoral, como as interleucinas: IL 4, IL 6, IL 10 e IL 5, sendo este último importante na diferenciação da $\lg A^{(2)}$. Da mesma forma, reduções nas concentrações de IgA na mucosa salivar também não devem ser interpretadas como suscetibilidade das outras regiões da mucosa ou dos demais segmentos da resposta imunológica.

\section{IGA-S E EXERCÍCIO}

A classificação do nível de esforço físico como de intensidade alta, moderada ou intermitente é normalmente estabelecida por meio de parâmetros fisiológicos e metabólicos, como lactato sanguíneo, frequência cardíaca máxima (FCM), consumo máximo de oxigênio $\left(\mathrm{VO}_{2 \max }\right)$, índice de percepção de esforço (IPE), entre outros ${ }^{(46)}$. Exercícios moderados e intensos são aqueles cujas intensidades se situam em até e acima de $70 \%$ do $\mathrm{VO}_{2 \text { max }}$ respectivamente. O exercício intermitente, por sua vez, oscila constantemente entre essas faixas de intensidade ao longo do tempo, intercalados ainda com curtos períodos de rápido repouso.

\section{Exercício de intensidade alta}

Resultados observados na literatura convergem para o consenso de uma diminuição marcada das concentrações de lgA-s quanto mais intenso o exercício. Estudos encontraram reduções na concentração de IgA tanto durante como após um período prolongado de treinamento intenso no ciclismo ${ }^{(32,35)}$, na corrida ${ }^{(24)}$, na natação ${ }^{(47)}$, no triátlon ${ }^{(48)}$ e em atletas de caiaque ${ }^{(49)}$. Libicz et al. ${ }^{(34)}$ investigaram oito triatletas durante o Iron Tour da França e coletaram, diariamente, amostras de saliva quando os atletas acordavam, antes da etapa do dia e após cada dia de competição. O fluxo salivar foi significantemente menor após cada etapa, comparada com o estado basal. A concentração de IgA-s no estado basal diminuiu ao longo de todo o evento e a taxa de secreção de lgA-s dos atletas, quando acordavam, reduziu-se em quase $52 \%$ ao longo dos dias de competição.

Os possíveis fatores envolvidos na redução da IgA-s em atletas praticantes de exercício de alta intensidade não estão completamente esclarecidos, mas os padrões de ordem neuroendócrinos parecem exercer papel fundamental em todo o processo ${ }^{(50,51)}$. As células do sistema imune possuem receptores para $\beta$-endorfinas, catecolaminas, cortisol, hormônio do crescimento $(\mathrm{GH})$ e diversos outros mediadores envolvidos na reação ao estresse ${ }^{(52)}$. O exercício físico intenso aumenta os níveis plasmáticos de diversos hormônios estressores e que influenciam a resposta imune ${ }^{(53)}$. Níveis elevados de cortisol proporcionados pelo exercício intenso e de longa duração estão relacionados com a morte de células T e B imaturas, fazendo com que menos leucócitos maturados, vindos da medula óssea, entrem na circulação(1). Fleshner ${ }^{(50)}$ sugere que elevadas concentrações de cortisol são necessárias para suprimir a expressão de anticorpos, mas não são por si sós suficientes. Tiollier et al. ${ }^{(44)}$, entretanto, analisaram a concentração de cortisol salivar durante treinamento intenso e não observaram correlação com a redução dos níveis de IgA-s, corroborando os dados encontrados por McDowell et al. ${ }^{(54)}$ e Tharp e Barnes ${ }^{(55)}$, que também não identificaram relação entre cortisol e lgA-s em período de treinamento intenso.

A expressão de beta-adrenorreceptores nos linfócitos T, B, neutrófilos, macrófagos e células natural killer (NK) formam a base molecular para ação dessas substâncias diante de estímulos catecolinérgicos. O GH, por si só, não parece ser um grande ativador do sistema imune a partir de estímulos do exercício, mas, quando associado à epinefrina, é responsá- vel pelo recrutamento de neutrófilos para o sangue ${ }^{(1)}$. Hormônios como testosterona, estrogênio, $\beta$-endorfinas, entre outros, também parecem influenciar a resposta imune ${ }^{(1)}$. A quantidade de receptores adrenérgicos e a eficiência do sistema de transdução AMPc diferem nos diversos tipos de células imunocompetentes ${ }^{(56)}$, de modo que linfócitos B, células precursoras de lgA, apresentam menos receptores em relação às outras células, possuindo somente mais receptores do que os linfócitos TCD4+(57).

Desse modo, ao contrário do que se verifica nos achados envolvendo estudos com animais, não se observa entendimento entre os realizados em seres humanos com relação a ação direta do fator hormonal sobre a IgA-s, a fim de explicar sua redução em treinamento intenso e, sobretudo, os mecanismos subjacentes associados a essa comunicação entre os sistemas nervoso, endócrino e imunológico. Contudo, esses sistemas exercem influência considerável sobre os elementos da resposta imune celular, que não pode ser negligenciada mesmo do ponto de vista da resposta imune humoral. Para tanto, Gomez-Merino et al. ${ }^{(58)}$ analisaram a concentração de IgA-s em 26 homens num período de cinco dias, durante três semanas de treinamento militar. Os resultados apontaram para um declínio da imunidade da mucosa salivar, com redução nos níveis de lgA e elevação plasmática de IL 6. A expressão dessa citocina é derivada da contratilidade das fibras musculares, uma vez que durante exercício intenso a liberação de IL 6 pelos monócitos é diminuída ${ }^{(59)}$. A IL 6 induz a liberação de cortisol, diminui a circulação das células Th1, estimula diretamente a produção de citocinas das células Th2 e ainda promove a supressão do TNF-a, um potente ativador de inflamação(60). Como as células Th1 promovem primeiramente proteção contra vírus, a liberação de IL 6 pelo exercício pode diminuir essa proteção viral, sendo mais uma possível razão da suscetibilidade de atletas à ITRS.

\section{Exercício de intensidade moderada}

O exercício físico moderado prévio a um exercício intenso parece minimizar as situações agressivas ocasionadas por este último ao sistema imune, por meio de mecanismos adaptativos de tolerância das células ${ }^{(46)}$. De fato, a prática regular de atividade física parece estar relacionada com a melhora dos padrões imunológicos de forma geral(61); entretanto, muitos desses trabalhos foram conduzidos por modelo animal ou tiveram abordagem imunológica abrangente ${ }^{(62-64)}$, de modo que os realizados com seres humanos e avaliando especificamente lgA-s e exercício moderado não apresentam resultados consensuais.

O modelo de J shaped curve (figura 1) relaciona o exercício moderado até certo ponto como benéfico, sendo responsável por melhoras no padrão imune em relação ao sujeito sedentário e que, uma vez ultrapassado determinado grau de esforço tendendo ao intenso, a função imune seria prejudicada, expondo o indivíduo a um maior risco de ITRS(8).

Segundo Matthews et al. ${ }^{(19)}$, a prática diária de exercício moderado reduz em quase 30\% a probabilidade de se contrair ITRS. NehlsenCannarella et al. ${ }^{(65)}$ observaram aumento de $20 \%$ de imunoglobulinas

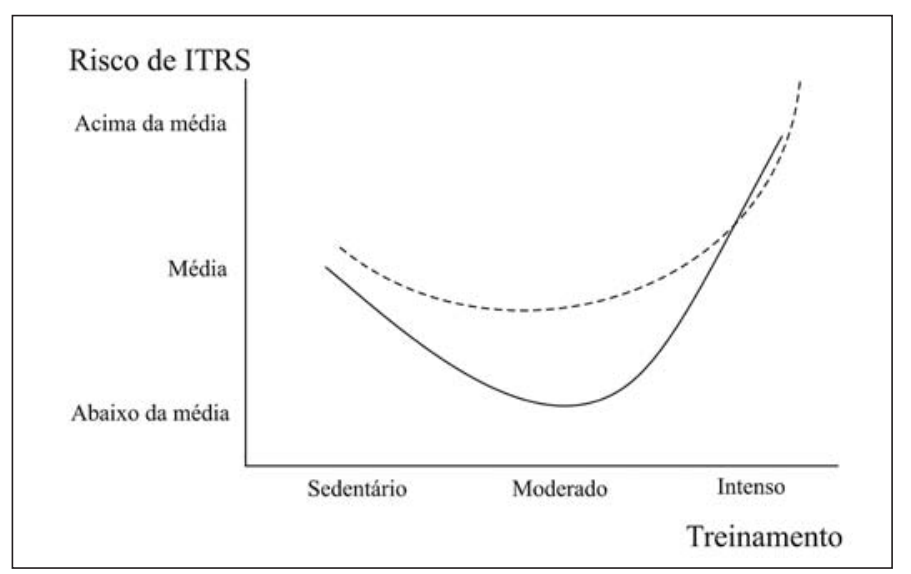

Figura 1. Modelo J shaped da relação entre infecções do trato respiratório superior (ITRS) e volume de exercício. Adaptado de Nieman ${ }^{(8)}$. 
séricas e outras variáveis circulantes do sistema imune entre a sexta e a $15^{\text {a }}$ semana de treinamento moderado. Housh et al. ${ }^{(20)}$, entretanto, afirmam não haver alterações na resposta de lgA-s durante o exercício de intensidade moderada, corroborando os resultados encontrados por McDowell et al. ${ }^{(66)}$, que também não encontraram alterações na lgA-s em resposta à corrida com intensidade moderada.

Dados inconsistentes podem ser reflexos da utilização de diferentes protocolos de exercício e do complexo controle de variáveis intervenientes, que podem, de forma independente, influenciar a função do sistema imune, como a dieta dos atletas, o período de competição, as viagens e o estresse psicológico(46). A forma pela qual os resultados de IgA-s são apresentados também deve ser observada para efeito metodológico (quadro 1). Os resultados de lgA são apresentados pelos estudos de várias formas: pela concentração absoluta; pela taxa de secreção (fluxo x concentração); em relação à albumina salivar; e em relação à osmolaridade da saliva. Alguns estudos ainda expressam o nível de IgA-s também em relação ao total de proteínas ${ }^{(15)}$, enquanto outros acreditam que a utilização desse método é inadequada (67). Uma explicação seria a hipótese, confirmada em estudo utilizando modelo animal, de que a secreção de IgA na saliva é diferente em relação à secreção de outros fluidos e proteínas salivares ${ }^{(68)}$, não tendo correlação com a taxa de secreção de $\lg A-s^{(69)}$. Além disso, a secreção de $\operatorname{lgA}$-s e proteínas responderia também de forma diferente à ação de colinérgi$\cos$, beta e alfa- adrenérgicos ${ }^{(70)}$. A taxa de secreção, portanto, é a forma mais recomendada de apresentação, uma vez que representa a disponibilidade total de IgA-s na superfície oral e corrige o efeito da secagem da cavidade oral pela respiração intensa durante o exercício ${ }^{(39)}$.

Em alguns casos, as diferenças entre os resultados dos estudos podem transcender as particularidades metodológicas e assumir características de cunho particular do indivíduo. Quando se estuda o sistema imune humano, a ação de fatores intrínsecos do hospedeiro, como permissibilidade e suscetibilidade, deve também ser levada em consideração. A análise desses conceitos discute a grande participação das características individuais. Um sujeito pode ter os níveis de lgA-s normalizados e apresentar alta suscetibilidade a algumas infecções, ou, de forma inversa, pode apresentar valores reduzidos nos níveis de lgA-s, mas mostrar baixa permissibilidade para contaminações. As razões dessa maior ou menor predisposição carecem de mais investigações.

Dois estudos recentes analisaram o comportamento da lgA-s de idosos em relação ao treinamento moderado e encontraram resultados positivos para elevação de lgA-s ao final do experimento. Akimoto et al.(30) submeteram seus avaliados a 12 meses de exercício moderado e Shimizu et al. ${ }^{(27)}$ envolveram os indivíduos do seu estudo em seis meses de treinamento. Ambos os trabalhos encontraram aumento nos níveis de lgA-s após o período de exercício, o que melhorou a imunidade da mucosa salivar dos sujeitos. Shimizu et al. ${ }^{(27)}$ explicam que a influência do exercício sobre as glândulas salivares por meio de estímulos hormonais poderia, de algum modo, alterar a composição de lgA da saliva. Eles especularam também sobre uma possível supraestimulação do receptor plgR pelo exercício, que facilitaria o aumento da expressão de lgA-s. De fato, elevadas concentrações de epinefrina têm sido associadas a maior mobilização do receptor plgR ${ }^{(28,71)}$. Já Akimoto et al. ${ }^{(30)}$ relatam a dificuldade em esclarecer os fatores que levaram a esse aumento e não apontam, de forma contundente, os motivos da melhora da IgA-s. O aumento da indução no número da família 70-kDa da proteína de choque térmico (HSP70) pelo exercício enquanto modelo indutor de estresse ${ }^{72}$ parece proteger as células tímicas da apoptose, surgindo como outro mecanismo importante que explicaria uma possível minimização dos efeitos imunossupressores relacionados com o exercício intenso(46); no entanto, em relação à IgA-s, tais processos não são verificados de modo consistente.

Estudos longitudinais como os descritos anteriormente, que avaliam o comportamento da mucosa salivar em relação ao exercício por várias semanas ou meses, muitas vezes, oferecem limites de comparação porque não descrevem adequadamente a intensidade e o volume de treino durante o período estudado; fornecem apenas detalhes limitados da carga de treino, das atividades praticadas ou dos valores médios do esforço(41). Ademais, devido à maior facilidade de mensuração do esforço em atividades contínuas e laboratoriais, poucos estudos se dedicam a estudar esportes $\operatorname{coletivos}^{(73)}$ ou em situação real de competição ${ }^{(34)}$. Estudos futuros podem ser conduzidos no sentido de propor um modelo de exercício moderado que ajudaria nesse aumento de lgA, indicando tipo, intensidade e volume de exercícios que proporcionariam melhores benefícios.

\section{Exercício intermitente}

Analisando as mais diversas formas de exercício físico, principalmente os esportes acíclicos com bola, o que se observa é um prolongado período em exercício, porém, com intensidades variadas. A maioria dos esportes, como tênis, basquetebol, voleibol, entre outros, caracteriza-se por momentos de intensidade alta, intercalados com períodos de intensidade moderada ou rápido repouso. Essas atividades não se situam exatamente dentro de um conceito de alta e moderada intensidade, pois, normalmente, são realizadas em intensidade abaixo de $75 \%$ do $V_{2} O_{2 \max }$ e o tempo em que se permanece no esforço máximo é relativamente curto.

A partir dessas considerações, um estudo, recentemente, investigou se a concentração de IgA-s pode ser afetada por atividades intermitentes. Sari-Sarraf et al. ${ }^{(74)}$ analisaram oito homens durante a realização de dois testes em dias diferenciados. Num deles a concentração de IgA-s era monitorada durante a execução de um grupo de atividades padronizadas, com variação de intensidade, para simular uma partida de futebol. No outro teste, a IgA-s foi avaliada em uma atividade contínua, sem variação da intensidade. Os resultados demonstraram que os períodos irregulares de alta e baixa intensidade da simulação do futebol não foram suficientes para promover supressão significativa das concentrações de lgA-s, comparados com o exercício contínuo.

Utilizando a mesma metodologia para simular a intensidade de um jogo de futebol, Sari-Sarraf et al. ${ }^{(75)}$ investigaram em outro estudo: se o curto período de recuperação a que são submetidos alguns atletas afetaria as concentrações de lgA-s. Comparando com uma única sessão de 90 minutos de exercícios, simulando uma partida de futebol, os indivíduos se exercitaram em outra oportunidade durante duas sessões de mesma duração (90 minutos) cada, com 2h25min de recuperação entre cada sessão. A IgA da saliva foi analisada antes e imediatamente após cada sessão; os resultados demonstraram que o exercício de intensidade variada, mesmo com um período curto de recuperação, não provocou efeito algum sobre a IgA-s. Novas et al. ${ }^{(16)}$, entretanto, observaram que os estímulos envolvidos durante uma hora de uma partida de tênis foram suficientes para provocar reduções significativas nas concentrações de lgA-s.

Os exercícios com variação de intensidade também apresentam dados adversos e os resultados indicam que a intensidade e a duração do estímulo são determinantes para reduções na lgA-s. Atividades como o futebol e o tênis tiveram resultados diferenciados na expressão salivar da IgA-s. Talvez, uma única sessão de exercícios nos estudos de Sari-Sarraf et al. ${ }^{(74,75)}$ foi insuficiente para provocar alterações, de modo que, se fosse dada a oportunidade de análise da lgA-s ao longo de um período mais longo de treinamento, os resultados poderiam ter sido diferentes. Do mesmo modo, a metodologia do mesmo estudo se valeu de uma simulação da intensidade apresentada em uma partida de futebol; caso a IgA-s fosse observada em uma situação real de jogo, os resultados também poderiam ser diferentes, como no estudo de Novas et al. ${ }^{(16)}$, em que as amostras foram coletadas na situação real da prática do tênis.

A supressão imunológica advinda do estresse provocado pela intensidade aumentada do exercício, entretanto, assume características de efeito transitório, isto é, mudanças do número e função leucocitária impostas pelo exercício voltam aos valores normais dentro de três a 24 horas, dependendo da intensidade e duração do esforço ${ }^{(2)}$. Até mesmo as células NK parecem estar aumentadas nos atletas pós-exercício, mas se reduzem a valores normais depois de um período de repouso ${ }^{(76)}$. Ten- 
do em vista o elevado volume de treinamento e competição a que os atletas são submetidos, os momentos dedicados ao descanso são, por vezes, limitados, abrindo uma janela facilitadora para processos infecciosos. Esse repouso, portanto, configura não somente a ausência completa de atividade ou o período de sono, que também é importante, mas a realização de um esforço físico de intensidade leve a moderada, como forma de recuperação da atividade mais intensa, torna-se também fundamental para o atleta nesse momento de maior suscetibilidade. Da mesma forma, para o indivíduo que já apresenta algum comprometimento imune, o descanso dos exercícios intensos é fundamental para recuperação mais rápida e aprimorada do processo infeccioso.

\section{ASPECTOS INDIVIDUAIS RELEVANTES NO CONTROLE DA IGA-S}

Há poucas investigações dedicadas à análise da relação gêneroidade, IgA-s e exercício e os resultados são ainda controversos; quanto ao gênero, contudo, há indicações de que o fluxo salivar nos homens é maior do que nas mulheres, mas a concentração de lgA é maior nas mulheres do que nos homens ${ }^{(31)}$. Ou seja, o homem possui maior volume de saliva, mas reduzida concentração de lgA-s em relação à mulher. Shimizu et al. ${ }^{(27)}$ analisaram idosos durante um período de treinamento moderado e confirmam maior fluxo salivar nos homens, porém, não observaram diferença em relação ao gênero para a taxa de secreção de $\lg$ A. Estudos anteriores sugerem que a menor concentração de lgA-s nos homens possivelmente teria relação entre a área da superfície do trato respiratório superior e o tamanho do corpo ${ }^{(77)}$. Geralmente, os homens apresentam valores tanto de altura como de massa corporal maiores que as mulheres e, portanto, maior área do trato respiratório superior, o que explicaria a reduzida concentração de lgA-s dos homens em relação às mulheres e deixaria os homens mais suscetíveis à infecção.

Quanto à idade, observa-se que, devido a diminuição funcional ou baixa regulação do sistema imunológico com o passar dos anos a partir da idade adulta, a proteção imune estaria diminuída nos idosos e os jovens seriam mais resistentes a microrganismos patogênicos ${ }^{(78)}$. Diante desse fato, vale ressaltar a importância do maior impacto do treinamento moderado, para efeito de melhora dos padrões imunológicos, principalmente em idosos. Quando submetidos à atividade física, é o grupo em que se observa o maior percentual de melhora(30), uma vez que apresenta níveis menores de lgA-s. Poucos são os estudos dedicados a analisar a resposta da IgA-s ao exercício em $\operatorname{crianças~}^{(79,80)}$ e adolescentes ${ }^{(81)}$, de modo que os resultados encontrados para indivíduos jovens não deve ser aplicado em sua totalidade a sujeitos de outras faixas etárias. Três razões lógicas podem ser atribuídas para a predominância de estudos com sujeitos entre 18 e 30 anos: é a faixa de idade da maioria dos atletas de elite, da maioria da população fisicamente ativa e da comunidade universitária, onde os participantes, na maioria das vezes, são requisitados(41).
Embora seja notório que fatores psicológicos e ambientais afetam a resposta da IgA-s, não temos conhecimento de estudos relacionando essas variáveis e que tenham foco direcionado sobre o contexto da atividade física; em linhas gerais, o que se tem é a redução contínua das concentrações de lgA-s em indivíduos submetidos a momentos de estresse psicológico ${ }^{(82)}$ Deinzer et al. ${ }^{(82)}$ monitoraram ainda por 14 dias essa baixa concentração de anticorpo após o evento estressante, e os valores reduzidos de lgA-s mantiveram-se também nesse período. Esse fato leva a atentar para a importância de se treinar e adaptar o atleta para situações de pressão psicológica, sobretudo os mais jovens. Especulamos que momentos estressantes de competição, sejam pela obrigação de ganhar, de não perder ou a própria inexperiência em situações competitivas, podem levar a uma predisposição a infecções por redução das concentrações de anticorpos.

Não se pode negligenciar a ação tanto isolada como, sobretudo, conjunta do fator ambiental. O treinamento associado a determinadas épocas do ano, como o inverno, no qual a predisposição à infecção é aumentada, deve ser considerado em pesquisas que analisam a imunidade das mucosas. Sugerimos a realização de estudos a fim de se investigar o comportamento da IgA-s, principalmente em atletas que fazem viagens constantes e mudam frequentemente de condição ambiental, muitas vezes sem um processo de aclimatação adequado. Jogadores de futebol, por exemplo, necessitam, em um curto período de tempo, estar em lugares que apresentam condições ambientais adversas, ainda que na mesma época do ano. Nesses casos, é extremamente importante que o atleta não seja submetido a mudanças bruscas da condição ambiental e, sempre que possível, possibilitar o contato prévio com o ambiente em que será realizada a atividade.

\section{Nível de condicionamento}

Estudos indicam que as concentrações de lgA-s são menores em atletas de endurance, comparados com indivíduos sedentários ${ }^{(12)}$. No entanto, devido ao retorno da IgA-s aos níveis basais com o repouso, trabalhos mais recentes consideram que os valores de IgA-s dos atletas não são menores, comparados com não atletas, exceto quando aqueles estão engajados em períodos de treinamento intenso ${ }^{(83)}$. Francis et al.(21) ao contrário, observaram maior concentração dos valores de $\operatorname{lgA}$ em amostras de saliva coletadas de atletas de natação, durante 30 dias, do que em sujeitos considerados ativos e sedentários. Saygin et al. ${ }^{(73)}$ também encontraram diferenças nos valores basais de lgA-s entre jogadores de voleibol, corredores de longa distância e indivíduos sedentários. Os jogadores de voleibol apresentaram níveis mais elevados do que sedentários e corredores, enquanto estes exibiram níveis maiores do que aqueles. Essa menor concentração de lgA-s em relação ao sedentário e sujeitos ativos não torna os atletas de endurance clinicamente imunodeficientes, ou seja, o exercício de alta intensidade não deixa o atleta na iminência de contrair infecções graves, mas pode ser suficiente para pôr em risco a contaminação por infecções comuns, como as ITRS (2) , e, ainda que infectados, demorariam mais tempo do que um sedentário para se recuperar ${ }^{(41)}$.

Tabela 1. Síntese de procedimentos metodológicos adotados em investigação da lgA-s

\begin{tabular}{|c|c|c|c|c|c|}
\hline Autores & $\mathrm{n}$ & Característica da amostra & Atividade & Principal limitação metodológica & $\lg A-s$ \\
\hline Gleeson et al. ${ }^{(7)}$ & 26 & $\begin{array}{l}\text { Homens e mulheres nadadores profissio- } \\
\text { nais }\end{array}$ & $\begin{array}{l}\text { Aeróbica e anaeróbica de moderada a } \\
\text { intensa }\end{array}$ & $\begin{array}{l}\text { Informação insuficiente sobre a forma de coleta de saliva. (ex. uso } \\
\text { de estimulantes) }\end{array}$ & $\downarrow$ \\
\hline Nieman et al. ${ }^{(15)}$ & 98 & Homens e mulheres corredores treinados & Aeróbica intensa & $\begin{array}{l}\text { Compara resultados de estudos que se diferem quanto à forma de } \\
\text { apresentação de lgA-s (ex. total de proteína X fluxo salivar) }\end{array}$ & $\downarrow$ \\
\hline Novas et al. ${ }^{(16)}$ & 17 & Mulheres tenistas profissionais & Intermitente & ITRS avaliada subjetivamente & $\downarrow$ \\
\hline Klentrou et al. ${ }^{(18)}$ & 9 & Homens e mulheres sedentários & Aeróbico moderado & ITRS avaliada subjetivamente & $\uparrow$ \\
\hline Shimizu et al.(27) & 125 & Homens e mulheres idosos sedentários & Aeróbica e anaeróbica moderada & $\begin{array}{l}\text { Apresenta número de indivíduos substancialmente menor no } \\
\text { grupo controle em relação ao grupo exercitado }\end{array}$ & $\uparrow$ \\
\hline Akimoto et al.(30) & 45 & Homens e mulheres idosos sedentários & Aeróbica e anaeróbica moderada & $\begin{array}{l}\text { Imprecisão para se determinar qual atividade (aeróbica ou anae- } \\
\text { róbica) exerceu maior influência sobre a lgA }\end{array}$ & $\uparrow$ \\
\hline Laing et al. ${ }^{(35)}$ & 12 & Homens ciclistas profissionais & $\begin{array}{l}\text { Aeróbica } \\
\text { moderada em alta temperatura }\left(30^{\circ} \mathrm{C}\right)\end{array}$ & $\begin{array}{l}\text { Pouco tempo de monitoramento da } \\
\lg \text { A-s pós-exercício }\end{array}$ & $\leftrightarrow$ \\
\hline Sari-Sarraf et al..$^{(74)}$ & 8 & Homens praticantes de atividade física & Grupo de exercícios intermitentes & Carga física simulada e não investigada em situação real & $\leftrightarrow$ \\
\hline
\end{tabular}


A variação dos níveis de lgA-s entre os sujeitos é amplamente observada ${ }^{(84,85)}$ e a análise da porção biológica dessa variação é realizada a partir de dois componentes: o percentual de variação da lgA-s intrassujeitos para um mesmo grupo e entre os sujeitos para grupos diferentes. Francis et al. ${ }^{(21)}$ observaram que a variabilidade intrassujeitos era maior nos nadadores de elite do que no grupo ativo ou no sedentário. Isso indica que uma única amostra de saliva de um nadador de elite tem menor confiabilidade em relação à concentração média de IgA-s dos outros nadadores do que uma única amostra de saliva dos ativos ou sedentários. Em contrapartida, se ativos e sedentários possuem maior variabilidade intersujeitos do que os atletas de elite, essa população é, então, inapropriada para efeito de grupo controle em relação a estudos realizados com atletas de elite. As razões dessa maior variabilidade entre os atletas de elite, assim como demais influências dessa variação biológica, necessitam de mais investigações.

Do ponto de vista metodológico, é essencial a descrição clara do nível de condicionamento físico dos sujeitos. Nota-se, frequentemente, nos estudos sobre lgA, a utilização de terminologias genéricas, como: "indivíduos bem treinados", "com boa capacidade física", "atletas de elite", entre outros, que dificultam a análise dos resultados para efeito de comparação entre os estudos. A utilização de variáveis fisiológicas (ex:: $\mathrm{VO}_{2 \max }$ ) ou de treinamento (ex.: km/semana ou horas/dia) para caracterização da amostra minimiza essa variabilidade metodológica e facilita uma análise mais apropriada dos resultados.

\section{NUTRIÇÃO}

A nutrição é outro elemento que deve ser considerado para estudo do sistema imune e exercício. Indivíduos malnutridos apresentam declínios na imunidade, sobretudo na $\lg A-s^{(86)}$, prejudicando, consequentemente, a capacidade dos atletas ou praticantes de atividades físicas de se protegerem contra agentes patogênicos, ficando mais suscetíveis às infecções ${ }^{(87)}$.

Praticantes de exercício físico com o objetivo de emagrecer, em muitas ocasiões, restringem drasticamente o consumo energético, produzindo assim uma condição facilitadora para a redução de lgA-s. Em atletas, isso pode ocorrer em modalidades com rigor excessivo na manutenção do peso corporal, como ginástica, dança, ou quando a classificação das categorias por peso é necessária, como nas lutas. Esses atletas podem estar expostos a um quadro de ITRS devida a esses momentos de restrição calórica e o controle das concentrações de lgA nesse grupo se torna ainda mais importante.

Durante o exercício intenso há também maior produção de espécies reativas de oxigênio (ERO) e algumas células do sistema imune parecem ser sensíveis à presença elevada de radicais livres ${ }^{(88)}$. A suplementação com vitaminas antioxidantes ajuda a minimizar os efeitos desses radicais. O consumo de vitamina $C$, administrada três semanas antes da competição, reduziu a resposta de IL-6 e cortisol, diminuindo a incidência de ITRS em corredores de ultramaratona ${ }^{(89)}$.

Especula-se que os efeitos da estimulação do exercício e ingestão de cafeína promoveriam aumento na atividade simpática para níveis suficientemente capazes de influenciar a mobilização de IgA-s. Recentemente, Bishop et al. ${ }^{(90)}$ observaram que a ingestão de cafeína uma hora antes de exercício extenuante (90 minutos) resultou apenas em aumento temporário da concentração e secreção de IgA-s.

A suplementação com carboidratos durante o exercício é comum entre os atletas e tem se mostrado uma ação nutricional importante ${ }^{(91)}$, inclusive do ponto de vista imunológico ${ }^{(92)}$. Além de manter os níveis glicêmicos normalizados, a presença de glicose como fonte de energia atenua o aumento de hormônios estressores, como cortisol e GH, ajudando a diminuir a ação de outras citocinas pró-inflamatórias ${ }^{(93)}$.

Apesar de as células do sistema imune suprirem-se da energia do metabolismo da glicose, há evidências do uso da glutamina por linfócitos e macrófagos mesmo quando há energia suficiente ${ }^{(94)}$. A li- beração de glutamina ocorre por meio da musculatura esquelética e é diminuída em exercícios de alta intensidade, podendo influenciar a função dos linfócitos e macrófagos. Assim, a suplementação de glutamina poderia amenizar a redução de fatores do sistema imune após o exercício ${ }^{(94)}$. Contudo, alguns estudos, como o de Krzywkowski et al. ${ }^{(95)}$, encontraram resultados adversos. Onze atletas se exercitaram durante duas horas a $75 \%$ do $\mathrm{VO}_{2 \max }$ num cicloergômetro, enquanto Ihes eram oferecidos glutamina, proteína ou placebo. Nem a proteína nem a glutamina foram capazes de conter a queda nas concentrações de lgA-s. Não foi verificado também efeito do consumo de glutamina sobre a redução da lgA-s até 22 horas após o exercício( ${ }^{(95)}$.

Apesar dos resultados pouco expressivos, é importante considerar outras formas e modelos de investigação. Afinal, os efeitos de recursos nutricionais, como glutamina, vitaminas antioxidantes, cafeína, ácidos graxos ômega 3, entre outros, sobre a lgA-s são abordagens recentes e devem ser observadas com cautela; pesquisas nesse sentido devem ser estimuladas, para efeito de resultados mais consistentes e reveladores.

\section{TOLL-LIKE RECEPTORS}

Os toll-like receptors (TLR) ou receptores semelhantes ao toll são uma família de proteínas de membrana que servem como receptores de reconhecimento de padrão e estão envolvidos no reconhecimento de padrões moleculares associados a patógenos (PAMPs). Desempenham papel fundamental na detecção e na indução da atividade antibactericida, tanto pelo sistema imune inato como pelo adquirido(96).

O reconhecimento dos PAMPs pelos TLR induz uma série de respostas intracelulares, como o estímulo à produção de citocinas (IL 6, IL 8, TNF-a entre outras), para conter o antígeno, gerando várias respostas adaptativas importantes em monócitos, macrófagos e células dendríticas ${ }^{(97)}$. Seria interessante, desse modo, levar em consideração a ação dos TLR inclusive à luz da resposta imune humoral.

Por ser um tema recente, são poucos os estudos que se dedicaram a analisar a resposta do exercício em relação aos TLR. Tanto o exercício aeróbico agudo como o crônico de força têm sido associados à redução na expressão de TLR na superfície de monócitos ${ }^{(98,99)}$. Esses resultados permitem especular sobre mais um fator a respeito dos mecanismos subjacentes à depressão imunológica após o exercício, sobretudo o de alta intensidade. Em longo prazo, esse decréscimo de TLR pode significar efeito benéfico, uma vez que reduz, concomitantemente, a capacidade inflamatória dos leucócitos ${ }^{(96)}$.

Há, portanto, de se ter um olhar mais atento sobre os TLR e exercício, pois é um campo de estudo promissor. O desenvolvimento de novas tecnologias vai permitir procedimentos metodológicos mais precisos, abrindo caminho para perspectivas de trabalhos interessantes nos próximos anos. Além da relação entre TLR, IgA e exercício, há necessidade de buscar muitas explicações, como, por exemplo: como e por que a expressão dos TLR diminui; a relação com outras modalidades de exercício; a ação no exercício em diferentes situações ambientais, etc.

\section{CONSIDERAÇÕES FINAIS}

Não há dúvidas de que o exercício físico exerce influência sobre o comportamento do sistema imunológico, especialmente sobre a lgA-s, e que o controle dessa variável em atletas se torna extremamente relevante e viável, principalmente por se tratar de método prático e não invasivo. Contudo, os questionamentos remanescentes evidenciam certa carência no rigor das práticas metodológicas. Cabe aos estudos futuros, utilizando-se de novas tecnologias, sobretudo do avanço de técnicas laboratoriais em investigação molecular, elucidar os mecanismos biológicos que regulam ou modulam as alterações na IgA frente aos diversos modelos de exercício e de que forma uma condição facilitadora de infecção seria presenciada.

Todos os autores declararam não haver qualquer potencial conflito de interesses referente a este artigo. 


\section{REFERÊNCIAS BIBLIOGRÁFICAS}

1. Pedersen BK, Hoffman-Goetz L. Exercise and the immune system: regulation, integration, and adaptation. Physiol Rev. 2000;80:1055-81.

2. Gleeson M. Immune function in sport and exercise. J Appl Physiol. 2007;103:693-9.

3. Carlson LA, Headley S, DeBruin J, Tuckow AT, Koch AJ, Kenefick RW. Carbohydrate supplementation and immune responses after acute exhaustive resistance exercise. Int I Sport Nutr Exerc Metab. 2008;18:247-59.

4. Jimenez C, Mathieu J, Peinnequin A, Carter R 3rd, Alonso A, Melin B. Immune function during and after $60 \mathrm{~min}$ of moderate exercise wearing protective clothing. Aviat Space Environ Med. 2008;79:570-6.

5. Gleeson M. Mucosal immune responses and risk of respiratory illness in elite athletes. Exerc Immunol Rev 2000;6:5-42.

6. Pyne DB, Gleeson M. Effects of intensive exercise training on immunity in athletes. Int J Sports Med. 1998;19 (Suppl 3):S183-91.

7. Gleeson M, McDonald WA, Pyne DB, Cripps AW, Francis JL, Fricker PA, et al. Salivary IgA levels and infection risk in elite swimmers. Med Sci Sports Exerc. 1999;31:67-73.

8. Nieman DC. Exercise, infection, and immunity. Int J Sports Med. 1994:15(Suppl 3):S131-41.

9. Pyne DB. Regulation of neutrophil function during exercise. Sports Med. 1994;17:245-58.

10. Pedersen BK, Bruunsgaard H. How physical exercise influences the establishment of infections. Sports Med. 1995:19:393-400.

11. Ronsen O, Pedersen BK, Øritsland TR, Bahr R, Kjeldsen-Kragh J. Leukocyte counts and lymphocyte responsiveness associated with repeated bouts of strenuous endurance exercise. J Appl Physiol. 2001:91:425-34.

12. Tomasi TB, Trudeau FB, Czerwinski D, Erredge S. Immune parameters in athletes before and after strenuous exercise. J Clin Immunol. 1982;2:173-8.

13. Gleeson M, Pyne DB. Special feature for the Olympics: effects of exercise on the immune system: exercise effects on mucosal immunity. Immunol Cell Biol. 2000;78:536-44.

14. Mackinnon LT, Ginn E, Seymour GJ. Temporal relationship between decreased salivary IgA and upper respiratory tract infection in elite athletes. Aust J Sci Med Sport. 1993;25:94-99.

15. Nieman DC, Henson DA, Fagoaga OR, Utter AC, Vinci DM, Davis JM, et al. Change in salivary lgA following a competitive marathon race. Int J Sports Med. 2002;23:69-75.

16. Novas AM, Rowbottom DG, Jenkins DG. Tennis, incidence of URTI and salivary IgA. Int J Sports Med. 2003;24:223-9.

17. Nieman DC, Henson DA, Gusewitch G, Warren BJ, Dotson RC, Butterworth DE, et al. Physical activity and immune function in elderly women. Med Sci Sports Exerc. 1993;25:823-31.

18. Klentrou P, CieslakT, MacNeil M, Vintinner A, Plyley M. Effect of moderate exercise on salivary immunoglobulin A and infection risk in humans. Eur J Appl Physiol. 2002:87:153-8

19. Matthews CE, Ockene IS, Freedson PS, Rosal MC, Merriam PA, Hebert JR. Moderate to vigorous physical activity and risk of upper-respiratory tract infection. Med Sci Sports Exerc. 2002;34:1242-8.

20. Housh TJ, Johnson GO, Housh DJ, Evans SL, Tharp GD. The effect of exercise at various temperatures on salivary levels of immunoglobulin A. Int J Sports Med. 1991;12:498-500.

21. Francis JL, Gleeson M, Pyne DB, Callister R, Clancy RL. Variation of salivary immunoglobulins in exercising and sedentary populations. Med Sci Sports Exerc. 2005;37:571-8.

22. Delves PJ, Roitt IM. The immune system. First of two parts. N Engl J Med. 2000;343:37-49.

23. Souza RM, Lehn CN, Denardin OVP. Níveis sérico e salivar de imunoglobulina A em portadores de câncer de boca e orofaringe. Assoc Med Bras. 2003:49:40-44.

24. McDowell SL, Hughes RA, Hughes RJ, Housh DJ, Housh TJ, Johnson GO. The effect of exhaustive exercise on salivary immunoglobulin A. J Sports Med Phys Fitness. 1992;32:412-5.

25. Lamm ME. Current concepts in mucosal immunity IV. How epithelial transport of IgA antibodies related to host defense. Am J Physiol. 1998;274:G614-G617

26. Abbas AK, Lichtman AH. Imunologia celular e molecular. 5a ediçăo. Elsevier: Rio de Janeiro, 2005.

27. Shimizu K, Kimura F, Akimoto T, Akama T, Otsuki T, Nishijima T, et al. Effects of exercise, age and gender on salivary secretory immunoglobulin A in elderly individuals. Exerc Immunol Rev. 2007;13:55-66.

28. Carpenter GH, Proctor GB, Anderson LC, Zhang XS, Garrett JR. Immunoglobulin A secretion into saliva during dua sympathetic and parasympathetic nerve stimulation of rat submandibular glands. Exp Physiol. 2000:85:281-6.

29. Kimura F, Aizawa K, Tanabe K, Shimizu K, Kon M, Lee H, et al. A rat model of saliva secretory immunoglobulin: suppression caused by intense exercise. Scand J Med Sci Sports. 2008;18:367-72.

30. Akimoto T, Kumai Y, Akama T, Hayashi E, Murakami H, Soma R, et al. Effects of 12 months of exercise training on salivary secretory IgA levels in elderly subjects. Br J Sports Med. 2003;37:76-9.

31. Eliasson L, Birkhed D, Osterberg T, Carlén A. Minor salivary gland secretion rates and immunoglobulin A in adults and the elderly Eur J Oral Sci. 2006:114:494-9.

32. MacKinnon LT, Jenkins DG. Decreased salivary immunoglobulins after intense interval exercise before and afte training. Med Sci Sports Exerc. 1993;25:678-83.

33. Chicharro JL, Lucía A, Pérez M, Vaquero AF, Ureña R. Saliva composition and exercise. Sports Med. 1998:26:17-27. 34. Libicz S, Mercier B, Bigou N, Le Gallais D, Castex F. Salivary IgA response of triathletes participating in the French Iron Tour. Int J Sports Med. 2006;27:389-94

35. Laing SJ, Gwynne D, Blackwell J, Williams M, Walters R, Walsh NP. Salivary IgA response to prolonged exercise in a hot environment in trained cyclists. Eur J Appl Physiol. 2005;93:665-71.

36. Marins JCB, Dantas E, Navarro S. Deshidratación y ejercicio físico, Selección. 2000;9:149-63.

37. Brito CJ, Marins JCB. Caracterização das práticas sobre hidratação em atletas da modalidade de judô no Estad de Minas Gerais. Rev Bras Ciên Mov. 2005;13:59-74.

38. Marins JCB, Ferreira FG. Nível de conhecimento dos atletas universitários da UFV sobre hidrataçăo. Fit \& Perform 2005:4:175-87

39. Walsh NP, Blannin AK, Clark AM, Cook L, Robson PJ, Gleeson M. The effects of high-intensity intermittent exercise on saliva IgA, total protein and alpha-amylase. J Sports Sci. 1999;17:129-134.

40. Bishop NC, Blannin AK, Armstrong E, Rickman M, Gleeson M. Carbohydrate and fluid intake affect the saliva flow rate and IgA response to cycling. Med Sci Sports Exerc. 2000;32:2046-51.

41. Gleeson M, Pyne DB, Callister R. The missing links in exercise effects on mucosal immunity. Exerc Immuno Rev. 2004;10:107-28.

42. Anderson SD, Kippelen P. Airway injury as a mechanism for exercise-induced bronchoconstriction in elite athletes. J Allergy Clin Immunol. 2008:122:225-35.

43. Fox PC, van der Ven PF, Sonies BC, Weiffenbach JM, Baum BJ. Xerostomia: evaluation of a symptom with increasing significance. J Am Dent Assoc. 1985;110:519-25.

44. Tiollier E, Gomez-Merino D, Burnat P, Jouanin JC, Bourrilhon C, Filaire E, et al. Intense training: mucosal immunity and incidence of respiratory infections. Eur J Appl Physiol. 2005:93:421-8.

45. Gleeson M, Pyne DB, Austin JP, Lynn Francis J, Clancy RL, McDonald WA, et al. Epstein-Barr virus reactivation and upper-respiratory illness in elite swimmers. Med Sci Sports Exerc. 2002;34:411-7.

46. Leandro CG, Castro RM, Nascimento E, Pithon-Curi TC, Curi R. Mecanismos adaptativos do sistema imunológico em resposta ao treinamento físico. Rev Bras Med Esporte. 2007;13:343-8.

47. Gleeson M, McDonald WA, Cripps AW, Pyne DB, Clancy RL, Fricker PA. The effect on immunity of long-term intensive training in elite swimmers. Clin Exp Immunol. 1995;102:210-6.

48. Steerenberg PA, van Asperen IA, van Nieuw Amerongen A, Biewenga A, Mol D, Medema GJ. Salivary levels of immunoglobulin A in triathletes. Eur J Oral Sci. 1997;105:305-9.

49. Mackinnon LT, Ginn E, Seymour GJ. Decreased salivary immunoglobulin A secretion rate after intense interva exercise in elite kayakers. Eur J Appl Physiol Occup Physiol. 1993;67:180-4.

50. Fleshner M. Exercise and neuroendocrine regulation of antibody production: protective effect of physical activity on stress-induced suppression of the specific antibody response. Int J Sports Med. 2000;21(Suppl 1):S14-9.
51. Pedersen BK, Steensberg A. Exercise and hypoxia: effects on leukocytes and interleukin-6-shared mechanisms? Med Sci Sports Exerc, 2002:34:2004-13.

52. Brenner I, Shek PN, Zamecnik J, Shephard RJ. Stress hormones and the immunological responses to heat and exercise. Int J Sports Med. 1998;10:130-143

53. Moynihan JA, Callahan TA, Kelley SP, Campbell LM. Adrenal hormone modulation of type 1 and type 2 cytokine production by spleen cells: dexamethasone and dehydroepiandrosterone suppress interleukin-2, interleukin-4 and interferon-gamma production in vitro. Cell Immunol. 1998:184:58-64.

54. McDowell SL, Hughes RA, Hughes RJ, Housh TJ, Johnson GO. The effect of exercise training on salivary immunoglobulin A and cortisol responses to maximal exercise. Int J Sports Med. 1992;13:577-80.

55. Tharp GD, Barnes MW. Reduction of saliva immunoglobulin levels by swim training. Eur J Appl Physiol Occup Physiol. 1990;60:61-4.

56. Miller AH. Neuroendocrine and immune system interactions in stress and depression. Psychiatr Clin North Am. 1998;21:443-63.

57. Kohut ML, Thompson JR, Lee W, Cunnick JE. Exercise training-induced adaptations of immune response are mediated by beta-adrenergic receptors in aged but not young mice. J Appl Physiol. 2004:96:1312-22

58. Gomez-Merino D, Chennaoui M, Burnat P, Drogou C, Guezennec CY. Immune and hormonal changes following intense military training. Mil Med. 2003;168:1034-8

59. Starkie RL, Rolland J, Angus DJ, Anderson MJ, Febbraio M. Circulating monocytes are not the source of elevation in plasma IL-6 and TNF- alpha levels after prolonged running. Am J Physiol Cell Physiol 2001;280:C769-C774.

60. Starkie R, Ostrowski SR, Jauffred S, Febbraio M, Pedersen BK. Exercise and IL-6 infusion inhibit endotoxin-induced TNF-alpha production in humans. FASEB J. 2003;17:884-6.

61. Dos Santos Cunha WD, Giampietro MV, De Souza DF, Vaisberg M, Seelaender MC, Rosa LF. Exercise restores immune cell function in energy-restricted rats. Med Sci Sports Exerc. 2004;36:2059-64.

62. Bacurau RF, Belmonte MA, Seelaender MC, Costa Rosa LF. Effect of a moderate intensity exercise training protocol on the metabolism of macrophages and lymphocytes of tumour-bearing rats. Cell Biochem Funct 2000:18:249-58.

63. Woods J, Lu Q, Ceddia MA, Lowder T. Special feature for the Olympics: effects of exercise on the immune system exercise-induced modulation of macrophage function. Immunol Cell Biol. 2000;78:545-53.

64. Nascimento E, Cavalcante T, Pereira S, Palmeira A, Rocha MC, Viana MT, et al. O exercício físico crônico altera o perfil leucocitário e a taxa de fagocitose de ratos estressados. Rev Port Cien Desp. 2004;4:26-33.

65. Nehlsen-Cannarella SL, Nieman DC, Balk-Lamberton AJ, Markoff PA, Chritton DB, Gusewitch G, et al. The effects of moderate exercise training on immune response. Med Sci Sports Exerc. 1991;23:64-70.

66. McDowell SL, Chaloa K, Housh TJ, Tharp GD, Johnson GO. The effect of exercise intensity and duration on salivary immunoglobulin A. Eur J Appl Physiol Occup Physiol. 1991;63:108-11.

67. Blannin AK, Robson PJ, Walsh NP, Clark AM, Glennon L, Gleeson M. The effect of exercising to exhaustion at different intensities on saliva immunoglobulin A, protein and electrolyte secretion. Int J Sports Med. 1998;19:547-52.

68. Proctor GB, Carpenter GH, Garrett JR. Sympathetic decentralization abolishes increased secretion of immunoglobulin A evoked by parasympathetic stimulation of rat submandibular glands. J Neuroimmunol. 2000;109:147-54

69. Miletic ID, Schiffman SS, Miletic VD, Sattely-Miller EA. Salivary IgA secretion rate in young and elderly persons, Physiol Behav. 1996;60:243-8.

70. Proctor GB, Garrett JR, Carpenter GH, Ebersole LE. Salivary secretion of immunoglobulin A by submandibular glands in response to autonomimetic infusions in anaesthetised rats. J Neuroimmunol. 2003;136:17-24.

71. Carpenter GH, Proctor GB, Ebersole LE, Garrett JR. Secretion of IgA by rat parotid and submandibular cells in response to autonomimetic stimulation in vitro. Int Immunopharmacol. 2004:4:1005-14.

72. LunzW, Oliveira EC, Neves MTD, Fontes, EPB, Dias, CMGC, Natali AJ. Anabolic steroid and exercise-induced cardiac stress protein (HSP72) in the rat. Braz J Med Biol Res. 2006;39:889-93.

73. Saygin O, Karacabey K, Ozmerdivenli R, Zorba E, Ilhan F, Bulut V. Effect of chronic exercise on immunoglobin complement and leukocyte types in volleyball players and athletes. Neuro Endocrinol Lett. 2006;27:271-6.

74. Sari-Sarraf V, Reilly T, Doran DA. Salivary IgA response to intermittent and continuous exercise. Int I Sports Med. 2006;27:849-55

75. Sari-Sarraf V, Reilly T, Doran DA, Atkinson G. The effects of single and repeated bouts of soccer-specific exercise on salivary IgA. Arch Oral Biol. 2007;52:526-32.

76. Shephard RJ, Shek PN. Effects of exercise and training on natural killer cell counts and cytolytic activity: a metaanalysis. Sports Med. 1999;28:177-95

77. Ménache MG, Hanna LM, Gross EA, Lou SR, Zinreich SJ, Leopold DA, et al. Upper respiratory tract surface areas and volumes of laboratory animals and humans: considerations for dosimetry models. J Toxicol Environ Health. 1997;11;50:475-506.

78. Shephard RJ, Shek PN. Exercise, aging and immune function. Int I Sports Med 1995:16:1-6.

79. Tharp, GD. Basketball exercise and secretory immunoglobulin A. Eur J Appl Physiol. 1991;63:312-314.

80. Dorrington M, Gleeson M, Callister R. Effect of exercise intensity on salivary IgA in children. J Sci Med Sport. 2003;6:46,

81. Nieman DC, Kernodle MW, Henson DA, Sonnenfeld G, Morton, DS. The acute response of the immune system to tennis drills in adolescent athletes. Res Q Exerc Sport. 2000;71:403-8.

82. Deinzer R, Kleineidam C, Stiller-Winkler R, Idel H, Bachg D. Prolonged reduction of salivary immunoglobulin A (slgA) after a major academic exam. Int J Psychophysiol. 2000;37:219-32.

83. Gleeson M. Immune system adaptation in elite athletes. Curr Opin Clin Nutr Metab Care 2006:9:659-65.

84. McDowell SL, Weir JP, Eckerson JM, Wagner LL, Housh TJ, Johnson GO. A preliminary investigation of the effect of weight training on salivary immunoglobulin A. Res Q Exerc Sport. 1993;64:348-51.

85. Burrows M, Bird SR, Bishop N. The menstrual cycle and its effect on the immune status of female endurance runners. J Sports Sci. 2002;20:339-44

86. Oliver SJ, Laing SJ, Wilson S, Bilzon JL, Walters R, Walsh NP. Salivary immunoglobulin A response at rest and after exercise following a $48 \mathrm{~h}$ period of fluid and/or energy restriction. Br J Nutr. 2007;97:1 109-16.

87. Calder PC, Jackson AA. Undernutrition, infection and immune function. Nutr Res Rev. 2000;13:3-29.

88. Barbosa KBF, Da Costa NMB, Alfenas RCG, De Paula SO, Minin VPR, Bressan JB. Oxidative stress: assessment of biomarkers. Nutrire 2008:33:111-28.

89. Peters EM, Goetzsche JM, Grobbelaar B, Noakes TD. Vitamin C supplementation reduces the incidence of postrace symptoms of upper-respiratory-tract infection in ultramarathon runners. Am J Clin Nutr. 1993;57:170-4.

90. Bishop NC, Walker GJ, Scanlon GA, Richards S, Rogers E. Salivary IgA response to prolonged intensive exercise following caffeine ingestion. Med Sci Sports Exerc. 2006:38:513-9.

91. Carvalho MV, Marins JCB, Garcia ES. The influence of water versus carbohydrate-electrolyte hydration on blood components during a 16-km military march. Mil Med. 2007;172:79-82.

92. Carlson LA, Headley S, DeBruin J, Tuckow AT, Koch AJ, Kenefick RW. Carbohydrate supplementation and immune responses after acute exhaustive resistance exercise. Int I Sport Nutr Exerc Metab. 2008:18:247-59.

93. Li TL, Gleeson M. The effects of carbohydrate supplementation during repeated bouts of prolonged exercise on saliva flow rate and immunoglobulin A. J Sports Sci. 2005;23:713-22.

94. Newsholme EA. Biochemical mechanisms to explain immunosuppression in well-trained and overtrained athletes. Int J Sports Med. 1994;15(Suppl 3):S142-7.

95. Krzywkowski K, Petersen EW, Ostrowski K, Link-Amster H, Boza J, Halkjaer-Kristensen J, et al. Effect of glutamine and protein supplementation on exercise-induced decreases in salivary lgA.J Appl Physiol. 2001:91:832-8.

96. Gleeson M, McFarlin B, Flynn M. Exercise and Toll-like receptors. Exerc Immunol Rev. 2006;12:34-53.

97. Pasare C, Medzhitov R. Toll-like receptors: linking innate and adaptive immunity. Microbes Infect. 2004;6:1382-7.

98. Lancaster Gl, Khan Q, Drysdale P, Wallace F, Jeukendrup AE, Drayson MT, et al. The physiological regulation of toll-like receptor expression and function in humans. J Physiol. 2005;563:945-55.

99. Stewart LK, Flynn MG, Campbell WW, Craig BA, Robinson JP, McFarlin BK, et al. Influence of exercise training and age on CD14+ cell-surface expression of toll-like receptor 2 and 4. Brain Behav Immun. 2005:19:389-97. 